\title{
Celebrating the ERS HERMES Self-Assessment Course
}

\author{
Robert Primhak ${ }^{1}$, Zuzana Tumova ${ }^{1}$, Amy Auer $^{1}$ and Daiana Stolz ${ }^{2}$ \\ Affiliations: ${ }^{1}$ European Respiratory Society, Lausanne, Switzerland. ${ }^{2}$ Universitätsspital Basel, Klinik für \\ Pneumologie, Basel, Switzerland. \\ Correspondence: Zuzana Tumova, European Respiratory Society, Avenue Sainte-Luce 4, 1003 Lausanne, \\ Switzerland. E-mail: zuzana.tumovadersnet.org
}

@ERSpublications

The ERS HERMES self-assessment course has developed over the past 2 years into a well-established course giving the opportunity to access European standard formative assessments https://bit.ly/3ilfEHL

Cite this article as: Primhak R, Tumova Z, Auer A, et al. Celebrating the ERS HERMES Self-Assessment Course. Eur Respir J 2020; 56: 2002895 [https://doi.org/10.1183/13993003.02895-2020].

\section{Introduction}

The European Respiratory Society (ERS) HERMES self-assessment course is celebrating its third year in 2020. Although it has a longer history, the course in its current format was launched in 2017 and has provided quality assessment to over 500 respiratory specialists around the world (table 1 shows a list of locations). Between 2018 and 2019, the number of courses delivered doubled and the first paediatric self-assessment course was offered in 2019. The ERS HERMES self-assessment course continues to grow in both its popularity and geographical reach.

\section{Background}

In 2005, the European Respiratory Society (ERS) launched the former "HERMES" (Harmonised education in respiratory medicine for European specialists) initiative with the aim to harmonise standards of training and education across Europe for respiratory specialists. The first project focused on adult respiratory medicine for trainees and successfully developed:

1) a core syllabus describing the competencies required or recommended to become a respiratory specialist [1];

2) curriculum recommendations suggesting how competencies should be taught and learned;

3) an accreditation methodology for training centres; and

4) a voluntary European examination, "ERS HERMES examination", based on the syllabus to assess whether specialists have acquired the knowledge-based component of competence.

The second project focused on paediatric respiratory medicine and developed similar outputs: a syllabus, a curriculum, training centre accreditation and an examination in paediatric respiratory medicine.

The ERS HERMES examinations are therefore offered in two specialities: adult or paediatric respiratory medicine. Moreover, three categories are available depending on the level of training and career stage of the physician:

1) European Diploma: after completion of the national programme or in the final year of the respiratory speciality training; a Diploma and 51 continuing medical education (CME) credits by the European Board for Accreditation in Pneumology (EBAP) are awarded if successfully passed 


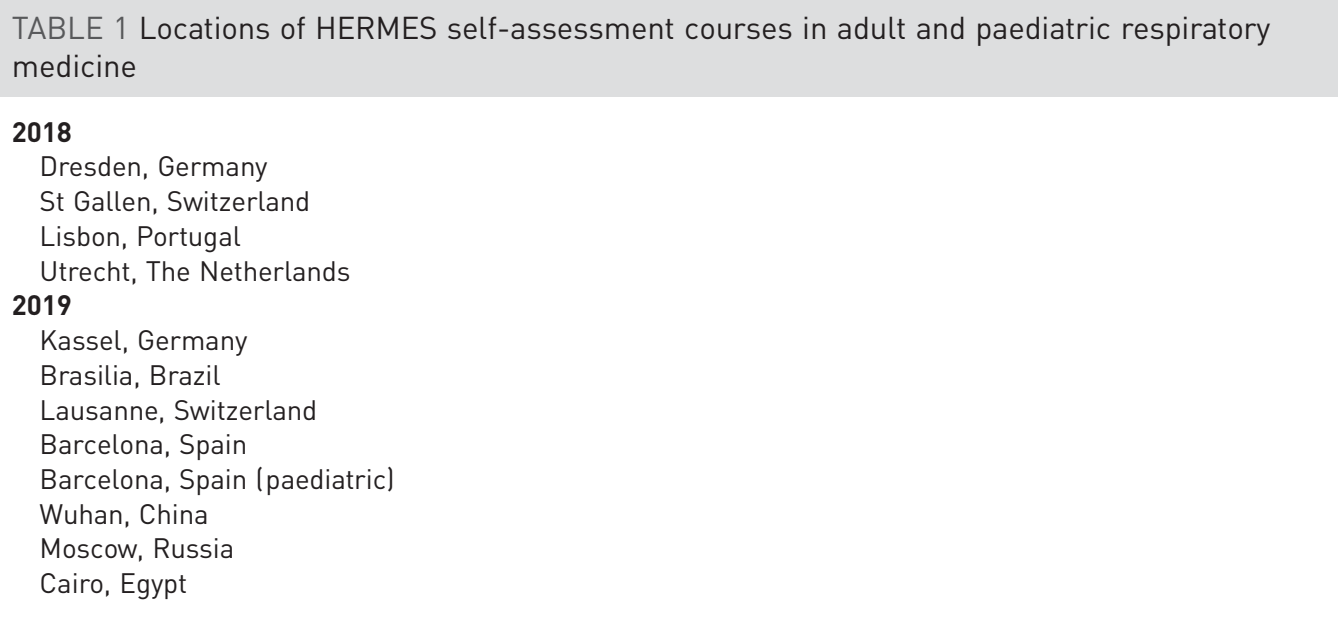

2) In-training: open to doctors during their respiratory training to benchmark their knowledge against European standards, worth six CME credits awarded by EBAP

3) Self-assessment: open to any qualified medical specialists, worth six CME credits awarded by EBAP

As there was an interest from participants taking the in-training category to receive explanations on examination questions, another activity, the ERS HERMES self-assessment course, was created.

\section{ERS HERMES self-assessment course}

The ERS HERMES self-assessment course is closely connected to the HERMES examination in adult and paediatric respiratory medicine. The self-assessment course is a smaller version of the full examination, giving participants an opportunity to check their ability and preparedness to pass the full examination. The course gives participants a chance to test their own knowledge against a European reference standard. The questions offer real-life clinical situations in which candidates must use their applied knowledge to answer.

So far offered exclusively in English, this activity gives participants 30 multiple-choice questions (MCQs) to answer in the first hour. The mock-examination is followed by a 2 -h review session of the questions with an ERS expert. This gives participants a chance to review the questions and answers with the guidance of an expert. It is a multidisciplinary learning environment in which participants are encouraged to ask questions and discuss.

The HERMES self-assessment course in adult respiratory medicine is offered multiple times throughout the year in different locations, mostly associated with activities of the national societies. Participating in the course is an ideal opportunity to prepare for taking the HERMES examination.

\section{Methodology of creating MCQs}

In both adult and paediatric respiratory medicine, the ERS HERMES self-assessment courses are made up of clinical cases presented in a mock-examination format. The cases are selected from a pool of MCQ questions for the ERS HERMES examination to give participants a sampling of the type of clinical situations found on the HERMES examination.

A rigorous review process and several quality controls, conducted by a multinational set of colleges under ERS supervision, are set in place for all questions prepared for the examination. The process begins with an MCQ writing workshop that takes place at the annual ERS International Congress. This workshop covers the basics of writing a good MCQ, which aim to assess the clinical competence of a specialist, test their knowledge, and their ability to know how to apply that knowledge in clinical situations. The MCQ writing workshop also covers the development of the different types of questions that are found on all HERMES examinations, A+, A-, and K-prime questions.

Writing a good MCQ question requires training and methodology. Through this workshop, the ERS not only provides future authors with training, but also introduces them to the ERS MCQ template, which is used across the ERS activities, the syllabus and blueprint used to ensure that there is balanced cross section of questions.

Between October and January, the ERS receives submissions of new questions, written by members of the ERS examination committee and MCQ authors. All submitted questions are then sent to the committee 
for review and are further discussed during committee meetings. During these meetings questions are rejected, revised or accepted. Committee members also ensure that there is a fair representation of all the different respiratory disease domains by referring to the blueprint. Accepted questions go through further internal ERS quality control checks.

\section{Benefits and highlights for participants sitting the course}

Participating in an ERS HERMES self-assessment course has a number of benefits. First of all, the course is an excellent self-assessment tool. It gives physicians an opportunity to evaluate their own level of knowledge at a high-quality European level. For respiratory specialists outside of Europe, it is a chance to test their knowledge against the European standard in respiratory medicine. Accredited by EBAP, sitting the self-assessment course also offers three CME credits.

Sitting the HERMES self-assessment course is also an exceptional final preparation for taking the annual HERMES examination. The adult course can be paired with study from the ERS Handbook: Self-Assessment in Respiratory Medicine (edited by Konrad E. Bloch, Thomas Brack and Anita K. Simonds), to maximise preparedness for the examination.

\section{Hosting a self-assessment course}

The ERS partners with national societies from around the world to host the ERS HERMES self-assessment courses in either adult or paediatric respiratory medicine. Through this partnership, national societies can offer their members a unique opportunity to test their knowledge of respiratory medicine in a convenient local setting. As part of a set fee, the national society is provided with examination booklets, course materials, logistical organisation and the collaboration with an ERS expert to deliver the course on site.

\section{Development of the self-assessment course}

One of the newer developments of the ERS HERMES self-assessment course is its expansion outside of Europe, specifically its introduction to Asia. The Chinese Thoracic Society hosted the inaugural course in Wuhan, China in September 2019, where there were 63 participants. One of the participants in China valued the course stating that "It's quite fantastic for me to have the experience of taking the examination that European respiratory physicians have." In 2019 the course in adult respiratory medicine was also delivered in Egypt and Russia; the first paediatric course took place in Barcelona, Spain.

\section{Conclusion}

The ERS HERMES self-assessment course has proven, already in a short period of time, to be a successful addition to other educational activities offered by the ERS. A local opportunity to access a European standard of formative assessments attracts local specialists and trainees in respiratory medicine. With the increasing interest in the HERMES examination, this course is also an ideal learning tool for all respiratory specialists intending to eventually sit the examination.

Conflict of interest: R. Primhak is Director of Assessment at the ERS. Z. Tumova is an ERS staff member. A. Auer is an ERS staff member. D. Stolz is ERS Education Council Chair and reports grants from AstraZeneca AG, Curetis AG and Boston Scientific, personal fees for lectures from AstraZeneca AG, Novartis AG, GSK AG, Roche AG, Zambon, Pfizer, Schwabe Pharma AG and Vifor AG, outside the submitted work.

\section{References}

1 Mitchell S, Rohde G. Introducing an updated international ERS syllabus for postgraduate training 2017. Breathe 2017; 13: e53-e55. 